\title{
Experimental and analytical investigations of volume change behaviour of saturated expansive soils in oedometer test
}

\author{
Misa Hiraga ${ }^{1, *}$, Hiroyuki Kyokawa ${ }^{1}$, and Junichi Koseki ${ }^{1}$ \\ ${ }^{1}$ The University of Tokyo, Department of Civil Engineering, 7-3-1 Hongo Bunkyo-ku Tokyo, Japan
}

\begin{abstract}
The chemical and mechanical behaviours of saturated bentonite were experimentally and analytically investigated. A series of oedometer tests on saturated bentonite was conducted. By replacing the cell fluid during the oedometer test, one-dimensional osmotic consolidation and swelling behaviour were observed. The experimental results were simulated numerically using a constitutive model by considering the influence of electrochemical phenomena of clay mineral crystals on the macrostructural behaviour. It was concluded that the typical mechanical swellability of water-saturated bentonite in oedometer test is affected by a positive dilatancy behaviour due to the lower shear strength. After the osmotic consolidation test, a lateral contraction of the specimen in the oedometer was observed; this affected the compressibility during the subsequent mechanical consolidation. It was also concluded that the concentration of $\mathrm{Na}^{+}$in the pore fluid affects the specific mechanical properties of bentonite.
\end{abstract}

\section{Introduction}

Expansive soils, of which bentonite is an example, are widely distributed around the world [1] and cause geotechnical problems like the unevenness of roads or tilting of infrastructures [2]. Bentonite is also regarded as a possible buffer material for radioactive waste disposal sites and has been investigated around the world for this purpose [3]. Therefore, a fundamental understanding of the mechanical characteristics of expansive soils, especially the volume change behaviour, is required for geotechnical engineering.

It is well known that the volume change of expansive soils is strongly affected by the chemical properties of the pore fluid [4]. For example, an increase/decrease in the cation concentration in the pore fluid causes volume shrinkage/expansion, called osmotic consolidation/swelling. Such osmotic behaviours of expansive soils have often been investigated [5-7]. However, quantitative evaluations and a generalization of these osmotic behaviours, especially when several ions are present in the environment, are still lacking; this is because expansive soils generally have low permeability and chemical experiments require extended periods of time.

On the other hand, many of the studies have intensively examined heavily compacted bentonite or bentonite mixtures in several countries [8-11], taking into account the realistic construction conditions of disposal sites. However, the actual results would be more complicated because they contain both osmotic and matric suctions. Therefore, experimental results that focus on the pure osmotic behaviour, which only can be observed in saturated expansive soils, are still required for a fundamental understanding of expansive soils.

For the purpose of quantitatively investigating the chemo-mechanical characteristics of expansive soils, especially the osmotic volume change behaviour, a series of oedometer tests on saturated bentonite was conducted in this study. During the mechanical consolidation and swelling in oedometer tests, the cell fluid was replaced with either distilled water or a $\mathrm{Na}^{+}$solution, and the osmotic consolidation or swelling was observed. These experimental results were simulated using a constitutive model considering the influence of the electro-chemical phenomena of clay mineral crystals on the macrostructural behaviour. By comparing experimental results and analytical results, the chemo-mechanical volume change behaviours of expansive soil in an oedometer test are theoretically discussed.

\section{Mechanical osmotic consolidation in oedometer test}

\subsection{Experimental methods}

All the experiments were conducted on initially watersaturated specimens of a sodium-type bentonite, Kunipia F, with a montmorillonite content of over $98.5 \%$. The basic properties of the bentonite used in this study are listed in Table 1.

The powdered clay was made into a paste by mixing with deionized water with a water content of around $500 \%$; it was then strained with a sieve ( $75 \mu \mathrm{m}$ opening) and deaerated. The paste was moulded into specimens of $5 \mathrm{~mm}$ height and $60 \mathrm{~mm}$ in diameter. The specimen height is low to shorten the testing period.

Table 1. Basic properties of bentonite (Kunipia F).

\begin{tabular}{ccc}
\hline $\begin{array}{c}\text { Liquid limit } \\
w_{\mathrm{L}}[\%]\end{array}$ & $\begin{array}{c}\text { Plastic limit } \\
w_{\mathrm{P}}[\%]\end{array}$ & $\begin{array}{c}\text { Soil particle density } \\
\rho_{\mathrm{s}}\left[\mathrm{g} / \mathrm{cm}^{3}\right]\end{array}$ \\
\hline 961 & 59 & 2.886 \\
\hline
\end{tabular}

\footnotetext{
* Corresponding author: misahiraga.23@geot.t.u-tokyo.ac.jp
} 


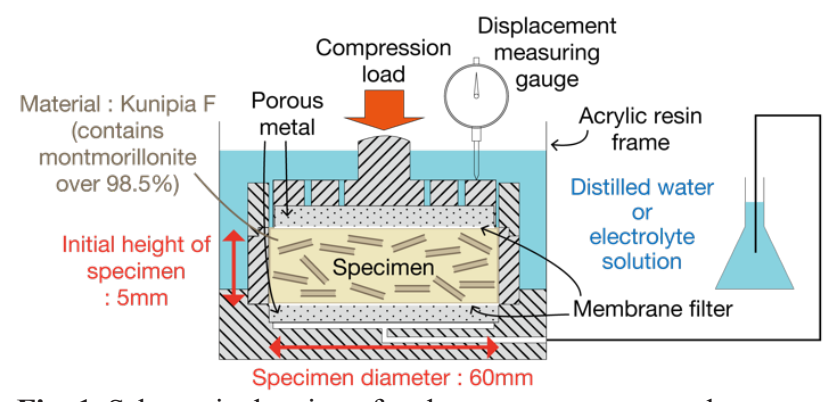

Fig. 1. Schematic drawing of oedometer apparatus used.

Table 2. Experiment cases conducted in this study.

\begin{tabular}{|c|c|}
\hline Case 1 & $\begin{array}{l}\text { 1. Mechanical consolidation } \\
\text { (32 kPa to } 1612 \mathrm{kPa}) \\
\text { 2. Mechanical swelling (unloading) } \\
\text { (1612 } \mathrm{kPa} \text { to } 32 \mathrm{kPa}) \\
\text { 3. Mechanical re-consolidation } \\
(32 \mathrm{kPa} \text { to } 1612 \mathrm{kPa})\end{array}$ \\
\hline Case 2 & $\begin{array}{l}\text { 1. Osmotic consolidation } \\
\text { (deionized water to } 1 \mathrm{~mol} / \mathrm{L} \mathrm{NaCl} \text { solution } \\
\text { under } 12 \mathrm{kPa}) \\
\text { 2. Mechanical consolidation } \\
(12 \mathrm{kPa} \text { to } 312 \mathrm{kPa}) \\
\text { 3. Mechanical swelling (unloading) } \\
(312 \mathrm{kPa} \text { to } 12 \mathrm{kPa}) \\
\frac{4 . \mathrm{Mechanical} \mathrm{re}-\mathrm{consolidation}}{(12 \mathrm{kPa} \text { to } 617 \mathrm{kPa})}\end{array}$ \\
\hline Case 3 & 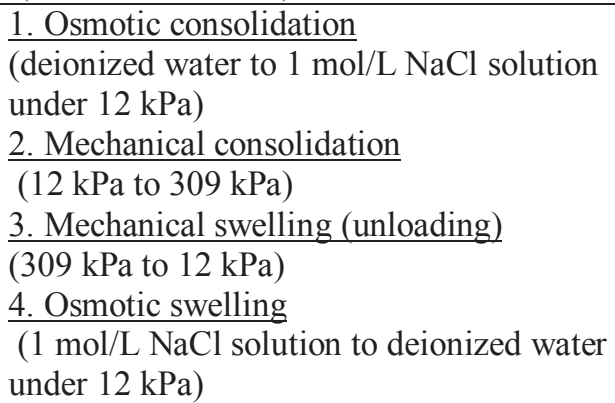 \\
\hline
\end{tabular}

The oedometer apparatus used in this study is described in Figure 1. The specimen in the oedometer is exposed to the cell fluid from both the top and bottom sides. During the mechanical loading and unloading, the cell fluid was replaced with either deionized water or a $1.0 \mathrm{~mol} / \mathrm{L} \mathrm{NaCl}$ solution, which causes osmotic consolidation (from deionized water to $\mathrm{NaCl}$ solution) and swelling (from $\mathrm{NaCl}$ solution to deionized water). In order to prevent the leakage of the clay particles from specimens, membrane filters (pore size: $0.2 \mu \mathrm{m}$ ) were inserted between the porous metal and the specimen at the top and bottom. All the specimens were saturated with deionized water under vertical stress: $32 \mathrm{kPa}$ in Case 1 and $12 \mathrm{kPa}$ in Cases 2 and 3. Each mechanical or osmotic consolidation step was ended when the increment of the vertical displacement became negligible for more than $6 \mathrm{~h}$, which is regarded as the end of primary consolidation in this study.

The series of experiments mainly consists of two parts: a mechanical process and an osmotic process. In order to investigate the mechanical consolidation and swelling properties with and without $\mathrm{Na}^{+}$solution, three

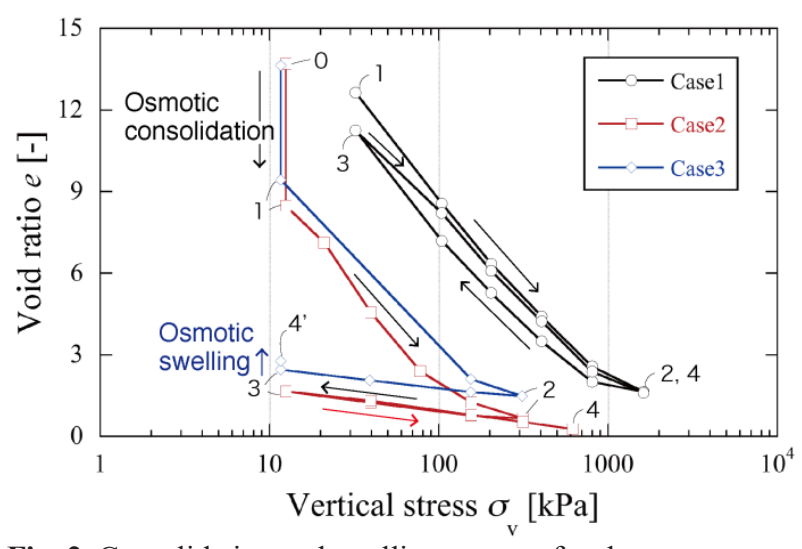

Fig. 2. Consolidation and swelling curves of oedometer tests.

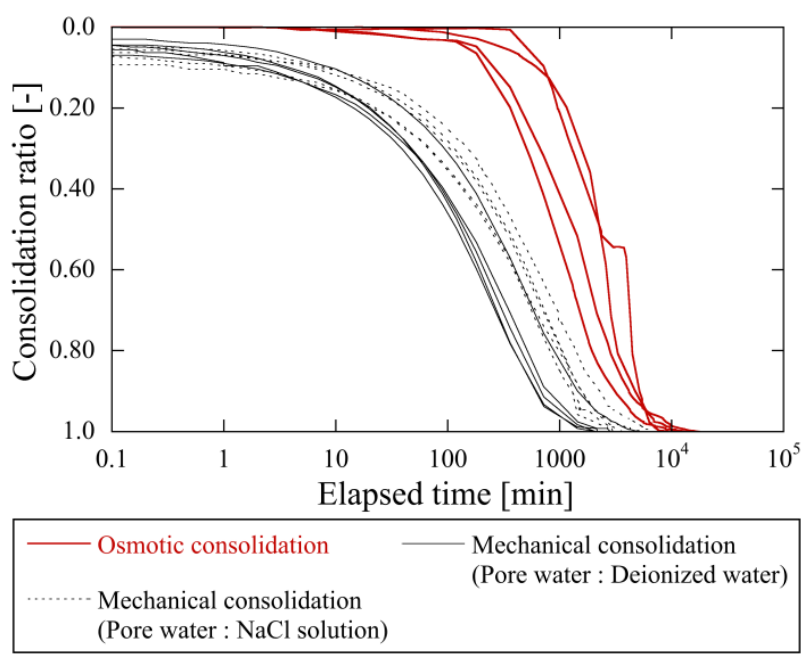

Fig. 3. Mechanical and osmotic consolidation ratio development with time.

patterns of oedometer tests were carried out. The procedures of each experiment are shown in Table 2. Case 1 consists of only a mechanical process, while for the other two cases, an osmotic consolidation process was conducted as the first loading step. For Cases 2 and 3, after osmotic consolidation, both specimens were mechanically consolidated to around $310 \mathrm{kPa}$ and swelled to $12 \mathrm{kPa}$. Then, the specimen was reconsolidated to $617 \mathrm{kPa}$ in Case 2, while in Case 3, the specimen was osmotically swelled at the lowest vertical stress.

\subsection{Experimental results}

Figure 2 shows the compression and swelling curves of each experiment. The void ratio shown in Figure 2 is influenced by the compression due to the membrane filters. For the water-saturated specimen (Case 1), the mechanical compression and swelling curves exhibited a steep slope, which represents typical compressibility and swellability of bentonite. In comparison, Cases 2 and 3, which included osmotic consolidation as the first loading step, showed a significantly lower mechanical swellability during the unloading process.

The osmotic consolidation process resulted in a considerable reduction in the void ratio for Case 2 (from 13.7 to 8.5 ) and Case 3 (from 13.6 to 9.4), whereas osmotic swelling process did not generate substantial void 
ratio change in Case 3. However, the volumetric strain, calculated by dividing the change of void ratio due to the osmotic process by the void ratio, was not negligible, which was $23.7 \%$ in the osmotic consolidation process and $-11.8 \%$ in the osmotic swelling process.

Figure 3 shows the consolidation ratio of both the mechanical and osmotic consolidations. Compared with the mechanical consolidation, it can be observed that the osmotic consolidation results in a delay of the initial compressibility. This can be explained by the fact that the osmotic consolidation process requires more time for the diffusion of $\mathrm{Na}^{+}$into the specimen, whereas for the mechanical consolidation process, the change of pore pressure immediately propagates after loading. Moreover, by comparing the consolidation ratios, it can be concluded that the pore fluid affects the mechanical consolidation development i.e., cases with $\mathrm{Na}^{+}$exhibited a slight delay near the last part of the consolidation.

Figure 4 shows the change of volumetric strain with time. Compared with osmotic consolidation, osmotic swelling resulted in more gradual and less displacement development.

Figure 5 shows the specimen immediately after the osmotic consolidation process; the specimen and the oedometer ring were easily separated. In a general mechanical consolidation test, the specimen adheres to the oedometer ring after the test. This difference was deduced to be a three-dimensional volume change due to the osmotic consolidation process. In a general oedometer test, where the lateral deformation is constrained, volume shrinkage by mechanical consolidation occurs only in the vertical direction. However, during osmotic consolidation, the specimen can contract in both vertical and lateral directions; this is because the osmotic consolidation behaviour is not constrained in lateral direction and can occur three-dimensionally even in oedometers. This observation suggests that we should consider that the deformation occurs three-dimensionally even in an oedometer test when investigating the influence of isotropic factors (e.g., chemical and thermal effects) on soil behaviour. In addition, the lateral shrinkage behaviour observed here could be partly attributed to the lower stress level $\left(\sigma_{\mathrm{v}}=12 \mathrm{kPa}\right)$ during the osmotic consolidation. Therefore, as future work, the effect of vertical stress on the lateral shrinkage should be investigated by conducting the osmotic consolidation at higher vertical stress level.

\section{Numerical Simulation}

\subsection{Constitutive model and parameters}

Element test simulations were conducted based on the constitutive model proposed by Kyokawa et al. [12], in which electrochemical phenomena on the surface of clay mineral crystals are considered. In this model, characteristic behaviours of expansive soils, namely osmotic consolidation and swelling behaviour, are described by coupling the interlaminar behaviour of clay mineral crystals and the soil skeleton behaviour. The interlaminar behaviour is derived from the electro-chemo-

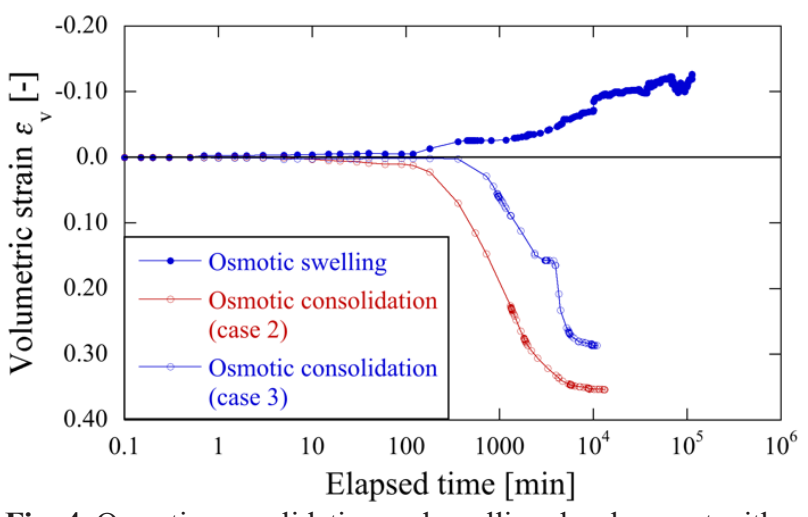

Fig. 4. Osmotic consolidation and swelling development with time.

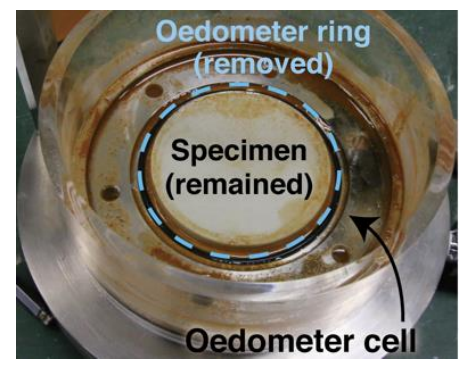

Fig. 5. Picture of a specimen after osmotic consolidation.

Table 3. Constitutive parameters used in the simulation. Parameters of consitutitive model (soil skeleton deformation)

\begin{tabular}{|c|c|c|c|}
\hline$\lambda$ & Compressi on index & - & 2.01 \\
\hline$\kappa$ & Swelling index & - & 1.40 \\
\hline$M$ & Critical stress ratio & - & 0.25 \\
\hline$v_{\mathrm{e}}$ & Poisson's ratio & - & 0.45 \\
\hline$e_{\mathrm{NC}}$ & Reference void ratio on NCL at $p=32.1 \mathrm{kPa}$ & - & 5.8 \\
\hline \multicolumn{4}{|c|}{ Material specification } \\
\hline \multirow[t]{2}{*}{$e_{0}$} & Initial void ratio (Casel) & - & 12.6 \\
\hline & Thital moid rito (Case2) & & 13.7 \\
\hline$e^{38}$ & Initial soil skeleton ratio & - & 5.8 \\
\hline$e^{i 1}{ }_{0}$ & Initial interl aminar void ratio & - & 6.8 \\
\hline
\end{tabular}

Physical constants

\begin{tabular}{clcr}
\hline$A_{\mathrm{h}}$ & Hamaker constant & $\mathrm{J}$ & $2.200 \mathrm{E}-20$ \\
\hline$k$ & Boltzmann constant & $\mathrm{J} / \mathrm{K}$ & $1.380 \mathrm{E}-23$ \\
\hline$e^{\prime}$ & Electronic charge & $\mathrm{C}$ & $1.609 \mathrm{E}-19$ \\
\hline Bentonite specification & & \\
\hline$t$ & Thickness of crystal & $\mathrm{m}$ & $9.60 \mathrm{E}-10$ \\
\hline$S$ & Specific surface area of ay stal & $\mathrm{m}^{2} / \mathrm{g}$ & 810 \\
\hline$C E C$ & Cation exchange capacity & $\mathrm{mEq} / \mathrm{g}$ & 0.405 \\
\hline$v$ & Valence of exchangeable cation & - & 1 \\
\hline$W_{0}$ & Parameter for the hydration force & $\mathrm{MJ} / \mathrm{m}^{2}$ & $1.00 \mathrm{E}-02$ \\
\hline$\chi_{0}$ & Parameter for the hydration force & $\mathrm{m}$ & $2.50 \mathrm{E}-10$ \\
\hline Pore water specification & & \\
\hline$T$ & Absolute temperature & $\mathrm{K}$ & 293.15 \\
\hline$\varepsilon$ & Electronic permittivity of pore water & $\mathrm{C}^{2} /(\mathrm{J} \cdot \mathrm{m})$ & $7.083 \mathrm{E}-10$ \\
\hline
\end{tabular}

mechanical coupling equilibrium of mineral crystals, which can be regarded as an extension of the DerjaguinLandau-Verwey-Overbeek (DLVO) theory [13-14]. By solving this interlaminar equilibrium, the interlaminar behaviour of clay crystals can be obtained. The soil skeleton behaviour is given by a general elastoplastic 
constitutive model for clay. In this study, the modified Cam clay model [15] was applied. The parameters used in the simulation are listed in Table 3 . Initial void ratios were obtained from experimental results. Parameters of the constitutive model and the initial interlaminar void ratio $e^{\mathrm{il}}{ }_{0}$ was determined through the simulation of Case 1.

\subsection{Simulation Results}

Simulation results for Cases 1 and 2 are shown in Figure 6. In the case of the water-saturated specimen, the simulation can reproduce the experimental results, namely the typical features of mechanical compressibility and swellability of bentonite.

However, this agreement is achieved not only because of the interlaminar behaviour but also the positive dilatancy behaviour after yielding. Figure 7 shows the simulation results of Case 1 with and without the consideration of the interlaminar behaviour. The result without the consideration of the interlaminar behaviour is same as the result of the modified Cam clay model, which is indicated by the dashed line in both graphs, namely only soil-skeleton (SS) behaviour. As can be seen, simulation with the interlaminar behaviour displayed a better agreement with the experimental result.

Let us discuss the influence of the dilatancy on the swelling behaviour. In the initial loading path $(1 \rightarrow 2)$, a difference in the compression line between both cases can be observed; this is due to the consideration of the interlaminar behaviour. In the subsequent unloading path $(2 \rightarrow 4)$, the inflection point $(3)$, after which the swelling lines become steeper, can be seen for both conditions. It can be understood from the stress paths (Figure 7(b)) that the soil yields at point (3) and the stress ratios are larger than critical state; thus, a positive dilatancy with strain softening occurs from point (3) to point (4) even in the one-dimensional unloading path. This inflection due to the strain softening behaviour is equally observed in each simulation case in Figure 7, regardless of the interlaminar behaviour. Therefore, the typical mechanical swelling behaviour of bentonite under one-dimensional compression can be reasonably explained by the positive dilatancy effect. It should also be noted that the low residual strength of bentonite $\left(\phi^{\prime}=6.9^{\circ}\right)$ contributes to this positive dilatancy for lower stress ratios.

Regarding the simulation results for Case 2, the osmotic consolidation behaviour is in good agreement with the experimental results. This consolidation behaviour is due to the increase in the ion concentration i.e., the interlaminar space between clay crystals is reduced when the osmotic pressure decreases in the model. On the other hand, the model could not accurately describe the mechanical consolidation and swelling behaviour after the osmotic consolidation. We first discuss the mechanical swelling process after the osmotic consolidation. In the experimental result of Case 2, the soil after the osmotic consolidation shows a linear unloading swelling behaviour on a logarithmic scale, while in Case 1, the distilled water-saturated soil has a nonlinear swelling curve. Therefore, we focused on the significant decrease in mechanical swellability after the

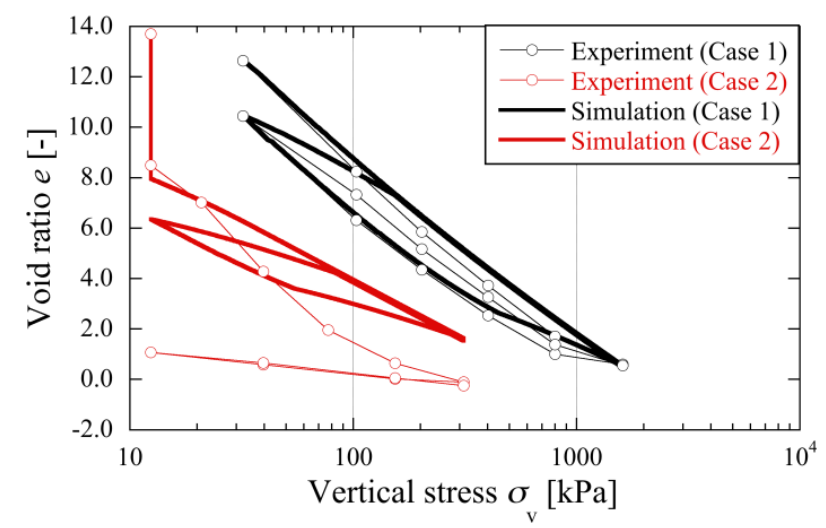

Fig. 6. Simulation results for experimental Cases 1 and 2.

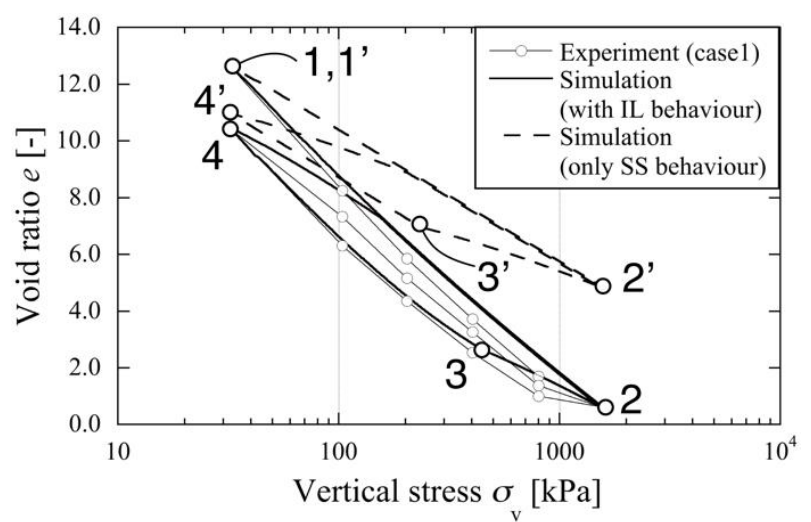

(a)

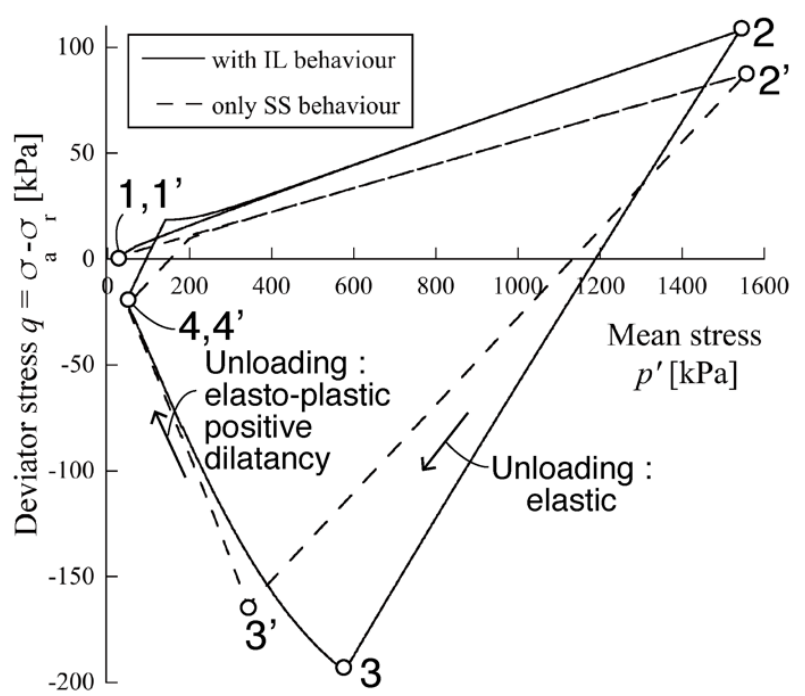

(b)

Fig. 7. Simulation results ((a) compression and swelling curves; (b) stress paths) for experimental Case 1, calculated with interlaminar behaviour and only soil skeleton behaviour

osmotic consolidation and a parametric study for the osmotically consolidated case (Case 2) was carried out.

Among the constitutive parameters, $M$ (critical stress ratio) and $v_{\mathrm{e}}$ (Poisson's ratio) were selected for the parametric study, because both have an effect on the swellability of the unloading process. $M$ represents the residual strength of the soil, which is same as the phase transformation line in the modified Cam clay model. $v_{\mathrm{e}}$ affects the elastic swelling behaviour, especially in the unloading path. 
The simulation result of Case 2 with the modified parameters $\left(M=0.58, v_{\mathrm{e}}=0.42\right)$ is shown in Figure 8. It can be observed from Figure 8 (a) that the modified parameters describe the low swellability after osmotic consolidation. Moreover, increasing the critical stress ratio $M$ makes the stiffness of the soil increase. As can be seen in Figure $8(\mathrm{~b})$, therefore, the higher deviator stress $\left(=\sigma_{\mathrm{v}}-\sigma_{\mathrm{r}}\right)$ is generated during the one-dimensional mechanical compression since the lateral stress is relatively low, it causes the yield surface at the end of the initial consolidation (at point 3) expands in the direction of the deviator stress in the $p-q$ plane. As a side note, point 2 is the stress state after the one-dimensional osmotic consolidation. Furthermore, the reduction of Poisson's ratio $v_{\mathrm{e}}$ mainly causes a sharp change in the deviator stress during unloading. Due to these two effects, the stress states in the unloading path $(3 \rightarrow 5)$ are in the elastic region. Therefore, no dilation occurs after yielding, which results in a gentle swelling curve. As a consequence of this parametric study, it can be suggested that the strength and rigidity of the soil skeleton will increase by replacing the fluid with a $\mathrm{Na}^{+}$solution. This phenomenon is related to a previous result [5], which shows an increase in residual shear strength of bentonite after exposure to salt solutions.

However, the simulation results with the modified parameters still cannot describe the mechanical consolidation behaviour after the osmotic consolidation in Case 2. A possible reason for this is that the reduction of the lateral constraints, as explained above, resulted in a 'uniaxial' stress state for the specimen, which in turn leads to the loss of lateral constraints in the oedometer. This would result in higher vertical compressibility after the osmotic consolidation in Case 2.

\section{Conclusion}

Oedometer tests on bentonite with osmotic consolidation/swelling and the corresponding numerical simulation were carried out in this study. From the comparison of experimental and simulation results, it was deduced that the typical mechanical swellability of bentonite in the unloading path, under the oedometer test conditions, is derived from the positive dilatancy behaviour. This behaviour is characterized by the properties of the soil, namely low residual strength, rather than the osmotic characteristics represented by the interlaminar behaviour. During the osmotic consolidation, not only an axial but also a lateral contraction of the specimen was observed under lower stress level in the experiment; this lateral contraction increases the compressibility during the subsequent onedimensional mechanical consolidation. Moreover, it can be noted from this phenomenon that the deformation occurs three-dimensionally even in an oedometer test when investigating the influence of isotropic factors (e.g., chemical and thermal effects) on soil behaviour. It was also confirmed that the penetration of a $\mathrm{Na}^{+}$solution reduces the mechanical swellability of bentonite; this could be explained by the change in the soil skeleton strength and rigidity. The investigations on the chemical

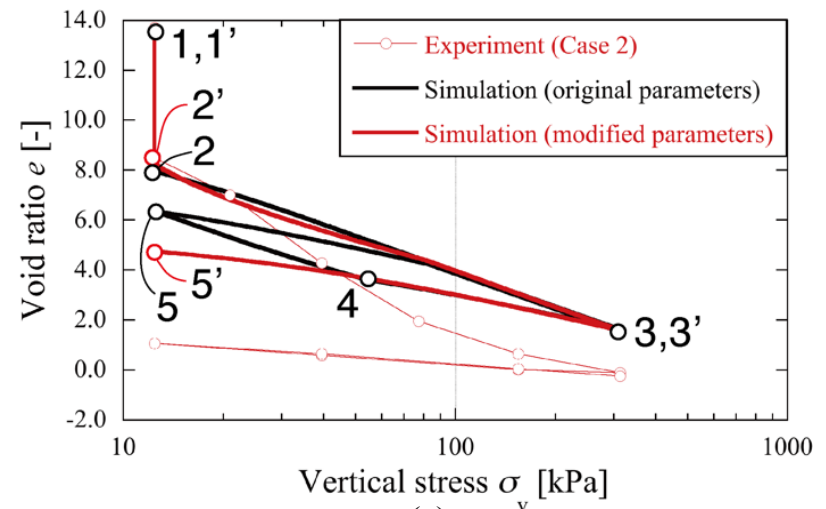

(a)

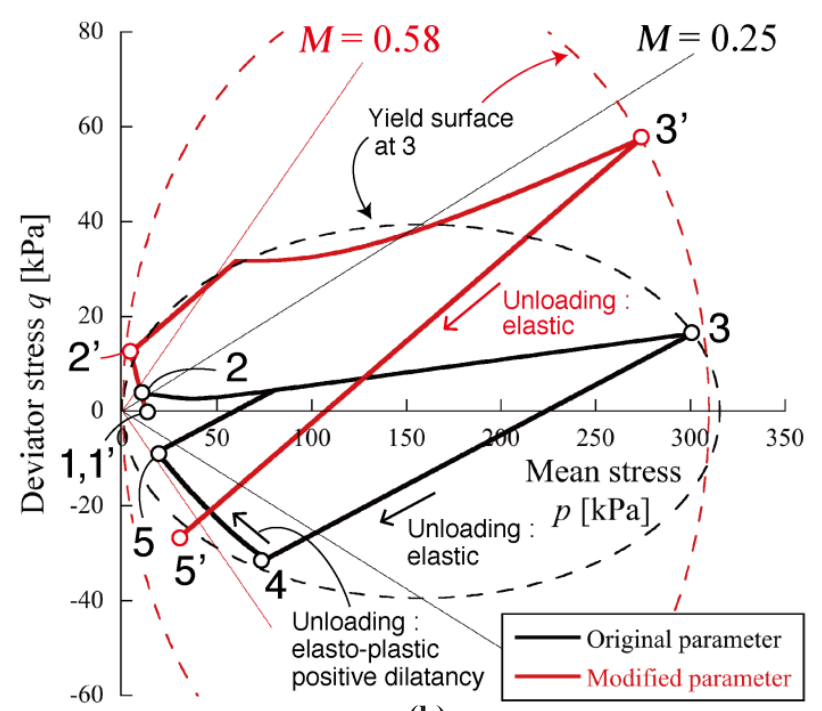

(b)

Fig. 8. Simulation results ((a) compression and swelling curves; (b) stress paths) for experimental Case 2 after modifying soil skeleton parameters

effect on the soil skeleton characteristics and its modelling will be future work.

\section{References}

1. C.D. Curtis, J. Geol. Soc. 147, 351 (1990)

2. J.D. Nelson, K.C. Chao, D.D. Overton, E.J. Nelson, Foundation Engineering for Expansive Soils (John Wiley \& Sons, Inc., 2015)

3. P. Delage, Y.J. Cui, A.M. Tang, J. Rock Mech. Geotech. Eng. 2, 111 (2010)

4. J.M. Mitchell, K. Soga, Fundamentals of soil behavior (John Wiley \& Sons, Inc., 3rd ed., 2005)

5. C. Di Maio, Geotechnique 46, 695 (1996)

6. G. Musso, E. Romero, A. Gens, E. Castellanos, Appl. Clay Sci. 23, 229 (2003)

7. T. Thyagaraj, S.M. Rao, Geotech. Geol. Eng. 31, 435 (2013)

8. S.M. Rao, T. Thyagaraj, H.R. Thomas, Geotechnique 56, 707 (2006)

9. S.M. Rao, T. Thyagaraj, Can. Geotech. J. 44, 520 (2007)

10. E. Castellanos, M.V. Villar, E. Romero, A. Lloret, A. Gens, Phys. Chem. Earth 33, S516 (2008) 
11. H. Komine, Y. Kazuya, S. Murakami, Can. Geotech. J. 46, 177 (2009)

12. H. Kyokawa, S. Ohno, I. Kobayashi, NUMGE 2018 9th European Conference on Numerical Methods in Geotechnical Engineering (2018)

13. B. Derjaguin, L. Landau, Acta Physicochim. URSS 14, 633 (1941)

14. E.J.W. Verwey, J.T.G. Overbeek, Theory of the Stability of Lyophobic Colloids (The interaction of so particles having an electric double layer) (Elsevier Publishing Company, 1948)

15. K.H. Roscoe, J.B. Burland, Eng. plasticity, 535 (1968) 